Supporting Information for:

\title{
Hybrid Pigments from Anthocyanin Analogues and Synthetic Clay Minerals
}

Gustavo Thalmer M. Silva, ${ }^{1}$ Karen Magno Silva, ${ }^{1,2}$ Cassio P. Silva, ${ }^{1}$ Josué M. Gonçalves, ${ }^{1}$ Frank H. Quina*1

${ }^{1}$ Instituto de Química, Universidade de São Paulo, Av. Lineu Prestes 748, Cidade Universitária, São Paulo 05508-000, Brazil

${ }^{2}$ Instituto Federal de Educação, Ciência e Tecnologia de São Paulo, Campus São Paulo, 01109-010 São Paulo, Brazil

* Corresponding author. E-mail address: quina@usp.br 
(a)

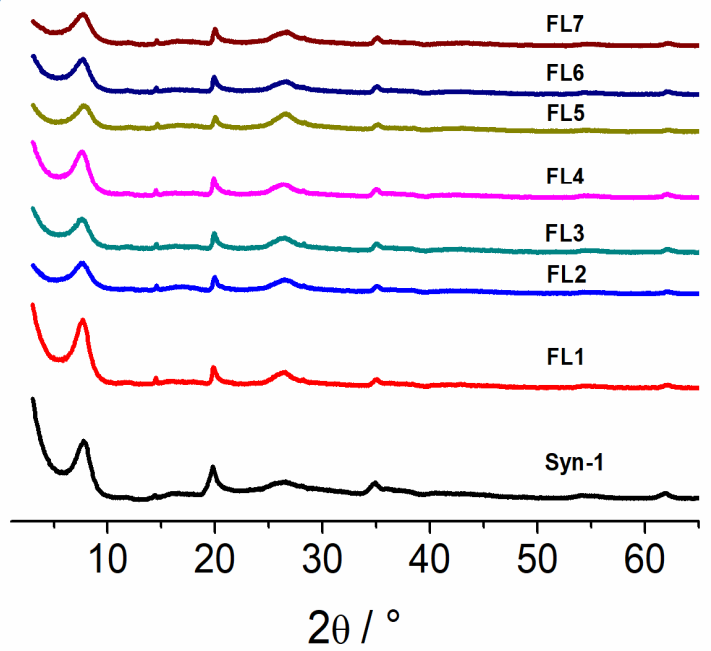

(b)

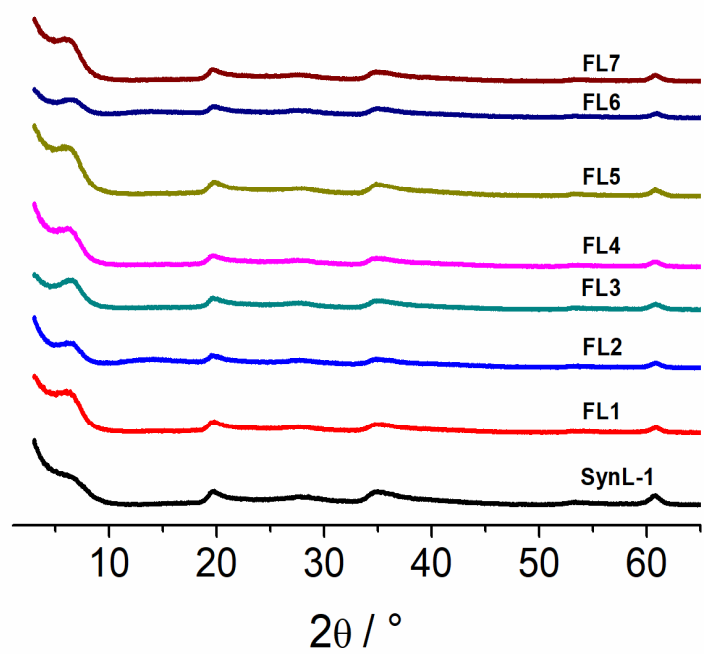

Figure S1. Powder X-ray diffractograms of the clays and FL/clay hybrid pigments: (a) SYn-1 and FL/SYn-1; (b) SYnL-1 and FL/SYnL-1.


Figure S2. Expansion of the low angle scattering peak of the powder X-ray diffractograms of the clays and FL/clay hybrid pigments: (a) SYn-1 and FL/SYn-1; (b) SYnL-1 and FL/SYnL-1. Color scheme as in Figure S1. 

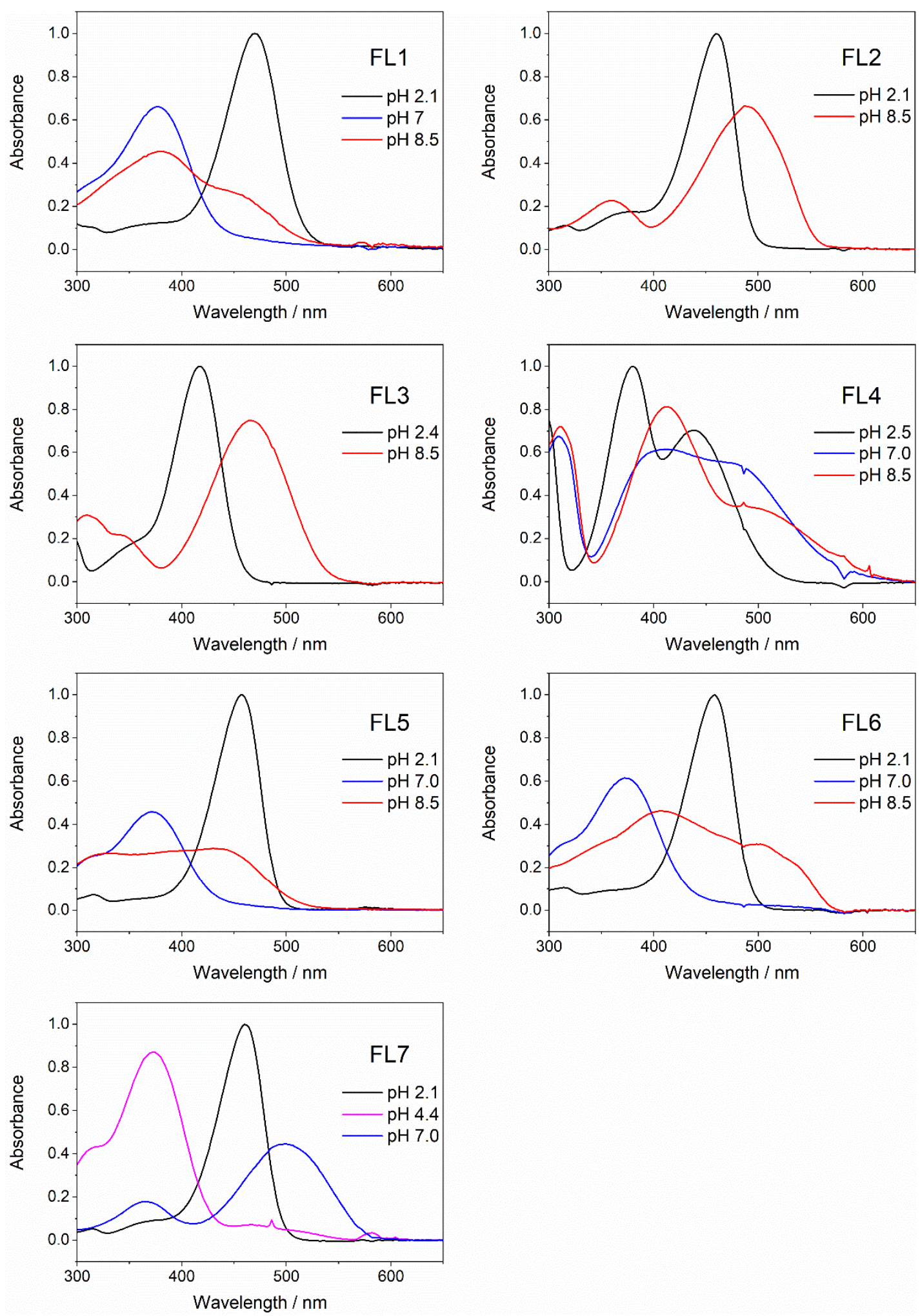

Figure S3. UV-Vis absorption spectra of the FL in aqueous solution at various $\mathrm{pH}$ values. All spectra were normalized relative to the long-wavelength absorption maximum of the flavylium cation form (black curve). 

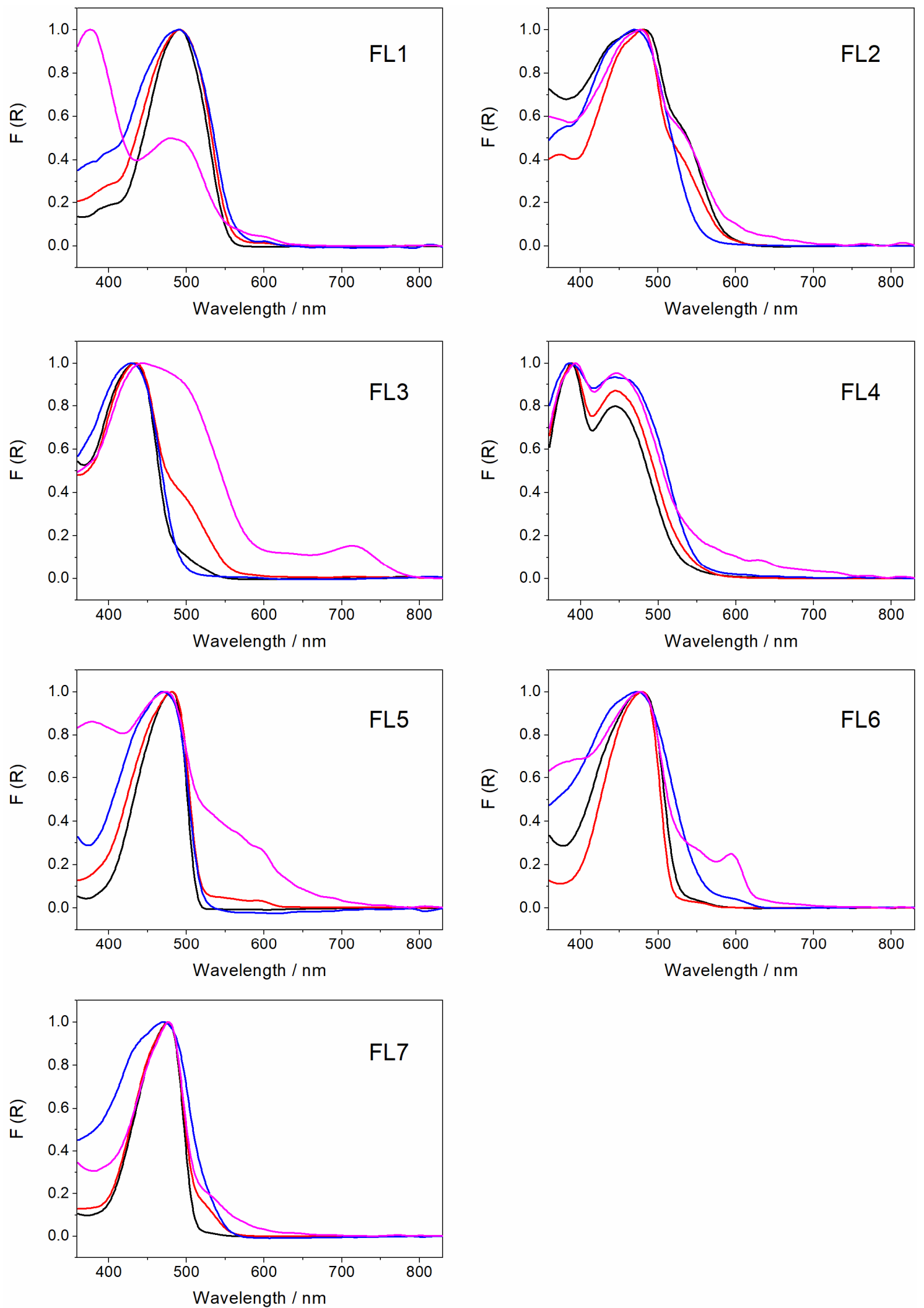

Figure S4. UV-vis-DR spectra (Kubelka-Munk mode) of FL/SYnL-1 and FL/SYn-1 samples, before (black and blue lines, respectively) and after (red and magenta lines, respectively) immersion in a $\mathrm{pH} 10$ aqueous buffer medium. 
Table S1. Total CIE 2000 color differences calculated from the CIELab data of the samples before and after thermal treatment at $100{ }^{\circ} \mathrm{C} .\left(\Delta \mathbf{E}_{1}\right)$ or $125^{\circ} \mathrm{C} .\left(\Delta \mathbf{E}_{2}\right)$.

\begin{tabular}{ccc} 
Sample & $\Delta \mathbf{E}_{1}$ & $\Delta \mathbf{E}_{2}$ \\
\hline FL1/SYn-1 & 4.7795 & 13.135 \\
FL1/SYnL-1 & 4.9979 & 11.1435 \\
FL7/SYn-1 & 19.2092 & 29.0314 \\
FL7/SYnL-1 & 13.5327 & 17.5923 \\
\hline
\end{tabular}

Table S2. CIE L*a*b* and C* $\mathrm{h}^{*}$ coordinate data for FL/SYn-1 samples, before and after immersion in a $\mathrm{pH} 10$ aqueous buffer medium.

\begin{tabular}{|c|c|c|c|c|c|c|}
\hline Sample & $\begin{array}{c}\text { Before (1) } \\
\text { or after (2) } \\
\text { pH } 10\end{array}$ & $\mathbf{L}^{*}$ & $a^{*}$ & $\mathbf{b}^{*}$ & $C^{*}$ & $\mathbf{h}^{*}$ \\
\hline \multirow[t]{2}{*}{ FL1/SYn-1 } & 1 & 75.4927 & 40.1861 & 47.2235 & 62.0079 & 49.6030 \\
\hline & 2 & 84.3957 & 15.8872 & 32.9476 & 36.5780 & 64.2568 \\
\hline \multirow[t]{2}{*}{ FL2/SYn-1 } & 1 & 75.4050 & 38.4558 & 86.8757 & 95.0065 & 66.1233 \\
\hline & 2 & 68.7984 & 37.8642 & 48.0099 & 61.1444 & 51.7380 \\
\hline \multirow[t]{2}{*}{ FL3/SYn-1 } & 1 & 88.1137 & -11.2776 & 62.2885 & 63.3012 & 100.2624 \\
\hline & 2 & 53.4512 & 20.9520 & 29.6129 & 36.2754 & 54.7195 \\
\hline \multirow[t]{2}{*}{ FL4/SYn-1 } & 1 & 74.6147 & 22.4009 & 83.3192 & 86.2780 & 74.9515 \\
\hline & 2 & 78.7419 & 5.7828 & 39.5838 & 40.0040 & 81.6884 \\
\hline \multirow[t]{2}{*}{ FL5/SYn-1 } & 1 & 82.5964 & 13.1935 & 63.0598 & 64.4252 & 78.1829 \\
\hline & 2 & 79.6420 & 9.2051 & 37.4636 & 38.5779 & 76.1954 \\
\hline \multirow[t]{2}{*}{ FL6/SYn-1 } & 1 & 70.4505 & 29.2990 & 76.2937 & 81.7261 & 68.9918 \\
\hline & 2 & 80.6065 & 9.4621 & 26.0755 & 27.7392 & 70.0555 \\
\hline \multirow[t]{2}{*}{ FL7/SYn-1 } & 1 & 79.5597 & 30.1822 & 89.6051 & 94.5518 & 71.3846 \\
\hline & 2 & 93.8147 & 7.8901 & 27.8076 & 28.9053 & 74.1592 \\
\hline
\end{tabular}


Table S3. CIE L*a*b* and C* $\mathrm{h}^{*}$ coordinate data for FL/SYnL-1 samples, before and after immersion in a pH 10 aqueous buffer medium.

\begin{tabular}{|c|c|c|c|c|c|c|}
\hline Sample & $\begin{array}{c}\text { Before (1) } \\
\text { or after (2) } \\
\text { pH } 10\end{array}$ & $\mathbf{L}^{*}$ & $a^{*}$ & $\mathbf{b}^{*}$ & $C^{*}$ & $\mathbf{h}^{*}$ \\
\hline \multirow[t]{2}{*}{ FL1/SYnL-1 } & 1 & 77.7810 & 31.2561 & 27.2182 & 41.4460 & 41.0498 \\
\hline & 2 & 83.0563 & 25.0246 & 30.4436 & 39.4087 & 50.5798 \\
\hline \multirow[t]{2}{*}{ FL2/SYnL-1 } & 1 & 47.3825 & 49.2332 & 47.1339 & 68.1580 & 43.7520 \\
\hline & 2 & 57.8978 & 46.2702 & 59.8199 & 75.6264 & 52.2783 \\
\hline \multirow[t]{2}{*}{ FL3/SYnL-1 } & 1 & 75.4797 & 15.8612 & 60.0289 & 62.0890 & 75.1992 \\
\hline & 2 & 71.5175 & 27.3566 & 65.6049 & 71.0802 & 67.3644 \\
\hline \multirow[t]{2}{*}{ FL4/SYnL-1 } & 1 & 70.7398 & 19.7249 & 71.2047 & 73.8862 & 74.5164 \\
\hline & 2 & 75.6068 & 20.4964 & 70.0215 & 72.9596 & 73.6844 \\
\hline \multirow[t]{2}{*}{ FL5/SYnL-1 } & 1 & 88.4473 & 4.8556 & 26.8644 & 27.2996 & 79.7547 \\
\hline & 2 & 86.5899 & 5.0535 & 39.6433 & 39.9641 & 82.7354 \\
\hline \multirow[t]{2}{*}{ FL6/SYnL-1 } & 1 & 69.4371 & 28.7445 & 48.8524 & 56.6816 & 59.5276 \\
\hline & 2 & 83.2320 & 16.3722 & 70.2184 & 72.1018 & 76.8753 \\
\hline \multirow[t]{2}{*}{ FL7/SYnL-1 } & 1 & 83.0336 & 12.0987 & 72.6680 & 73.6683 & 80.5474 \\
\hline & 2 & 73.5775 & 34.8731 & 69.5017 & 77.7601 & 63.3544 \\
\hline
\end{tabular}


Table S4. Total CIE 2000 color differences calculated from the CIELab data of the samples before and after $24 \mathrm{~h}$ immersion in a $\mathrm{pH} 10$ aqueous buffer medium.

\begin{tabular}{ccc}
\hline Sample & $\begin{array}{c}\Delta \mathbf{E}_{\mathbf{2 0 0 0}} \\
(\text { FL/SYn-1) }\end{array}$ & $\begin{array}{c}\Delta \mathbf{E}_{\mathbf{2 0 0 0}} \\
(\text { FL/SYnL-1) }\end{array}$ \\
\hline FL1/Clay & 22.8586 & 5.7283 \\
FL2/Clay & 14.2752 & 11.2774 \\
FL3/Clay & 53.1954 & 10.701 \\
FL4/Clay & 13.1825 & 3.848 \\
FL5/Clay & 10.2963 & 7.6758 \\
FL6/Clay & 16.1935 & 22.1809 \\
FL7/Clay & 20.1013 & 14.9166 \\
\hline
\end{tabular}

Table S5. Total CIE 2000 color differences relative to the $\mathrm{pH} 7$ aqueous solution of the dye at $10 \mathrm{~min}, 1 \mathrm{~h}, 24 \mathrm{~h}$ and 27 days after the addition of the clay.

\begin{tabular}{|c|c|c|c|c|c|}
\hline Sample & $\begin{array}{l}\Delta \mathbf{E}_{2000} \\
(\mathbf{t}=\mathbf{0})^{\mathbf{a}}\end{array}$ & $\begin{array}{c}\Delta \mathbf{E}_{2000} \\
(10 \mathrm{~min})\end{array}$ & $\begin{array}{c}\Delta \mathbf{E}_{2000} \\
(\mathbf{1} \mathbf{h})\end{array}$ & $\begin{array}{l}\Delta \mathbf{E}_{2000} \\
(24 \mathrm{~h})\end{array}$ & $\begin{array}{l}\Delta \mathbf{E}_{2000} \\
(27 \mathbf{d})\end{array}$ \\
\hline FL1/SYn-1 (pH 7) & $0^{\mathrm{b}}$ & 15.6506 & 18.9390 & 20.8482 & 22.2205 \\
\hline FL1/SYn-1 (pH 8) & 10.4139 & 11.5536 & 17.3729 & 19.5662 & 21.2332 \\
\hline FL1/SYnL-1 (pH 7) & $0^{\mathrm{c}}$ & 19.5514 & 21.9321 & 32.4652 & 33.6189 \\
\hline FL1/SYnL-1 (pH 8) & 8.7749 & 21.2332 & 20.2549 & 28.2952 & 31.3579 \\
\hline
\end{tabular}

